\title{
Broadening the Genetic Basis of Verticillium longisporum Resistance in Brassica napus by Interspecific Hybridization
}

\author{
W. Rygulla, R. J. Snowdon, C. Eynck, B. Koopmann, A. von Tiedemann, W. Lühs, and W. Friedt
}

First, second, sixth, and seventh authors: Department of Plant Breeding, Research Center for BioSystems, Land Use and Nutrition, Justus Liebig University, Heinrich-Buff-Ring 26-32, D-35392 Giessen, Germany; and third, fourth, and fifth authors: Department of Crop Sciences, Division of Plant Pathology and Crop Protection, Georg-August-University, Grisebachstrasse 6, D-37077 Göttingen, Germany. Accepted for publication 16 July 2007.

\begin{abstract}
Rygulla, W., Snowdon, R. J., Eynck, C., Koopmann, B., von Tiedemann, A., Lühs, W., and Friedt, W. 2007. Broadening the genetic basis of Verticillium longisporum resistance in Brassica napus by interspecific hybridization. Phytopathology 97:1391-1396.

Verticillium wilt caused by the vascular fungal pathogen Verticillium longisporum is one of the most important pathogens of oilseed rape (Brassica napus sp. oleifera) in northern Europe. Because production of this major oilseed crop is expanding rapidly and no approved fungicides are available for $V$. longisporum, long-term control of the disease can only be achieved with cultivars carrying effective quantitative resistance. However, very little resistance to $V$. longisporum is available within the gene pool of oilseed rape, meaning that interspecific gene transfer from related species is the only possibility for broadening levels of resistance

thesized by crossing the two progenitor species Brassica oleracea and Brassica rapa, hence resistant accessions of these two diploid species can be used as resistance donors. In this study a total of 43 potential $B$. rapa and $B$. oleracea resistance donors were tested with regard to their reaction to a mixture of two aggressive $V$. longisporum isolates, and resistances from diverse lines were combined by embryo rescue-assisted interspecific hybridization in resynthesized rapeseed lines. Progenies from crosses of the two B. rapa gene bank accessions 13444 and 56515 to the $B$. oleracea gene bank accessions BRA1008, CGN14044, 8207, BRA1398, and 7518 showed a broad spectrum of resistance in pathogenicity tests. Of 45 tested resynthesized lines, 41 lines exhibited a significantly higher level of resistance than the moderately $V$. longisporum-tolerant oilseed rape cultivar Express. These lines represent a promising basis for the combination of different resistance resources in new varieties.
\end{abstract} in current varieties. The amphidiploid species B. napus can be resyn-
Verticillium wilt caused by the fungal pathogen Verticillium longisporum (13) is one of the most important pathogens of oilseed rape (Brassica napus sp. oleifera) in northern Europe. The disease is especially prominent in northern Germany and Sweden, but it has also been reported to occur in Poland, France, southern Russia, and Ukraine (12). The fungus infects oilseed rape by colonizing the xylem vessels. Due to the production of fungal material and host reaction products the vascular system becomes blocked, meaning that heavily infected plants die due to water stress. At the same time microsclerotia are produced in the plant, causing symptomatic blackening of leaf veins or stems. With the decomposition of dead plant material the microsclerotia are released to the soil, where the fungus can survive for many years in this dormant form (19).

Oilseed rape is the most important oilseed crop in Europe and the production area is continuing to rise dramatically due to the high demand for oilseed rape oil, both as a healthy vegetable oil, and a renewable resource for the oleochemical industry. Because no approved fungicides are available for $V$. longisporum, longterm control of the disease can only be sustained with cultivars carrying effective quantitative resistance. Up to $70 \%$ yield loss due to disease-induced premature ripening has been observed in individual plants (9), and yield losses in the field can also be severe. Currently available commercial varieties are generally susceptible or exhibit only slight tolerance to V. longisporum.

Corresponding author: R. J. Snowdon

E-mail address: Rod.Snowdon@agrar.uni-giessen.de

doi:10.1094/PHYTO-97-11-1391

(C) 2007 The American Phytopathological Society
Intensive screening of available B. napus germplasm failed to identify resistance resources within the primary gene pool (11). On the other hand, because B. napus (genome AACC, $2 \mathrm{n}=38$ ) is an amphidiploid species that is derived from interspecific hybridizations between turnip rape (Brassica rapa L., syn. campestris; AA, $2 \mathrm{n}=20$ ) and cabbage (Brassica oleracea L.; CC, $2 \mathrm{n}=18$ ), the diverse gene pools of these two progenitor species can also be used as potential gene donors to broaden the resistance spectrum of the amphidiploid species. Nothing is known about the inheritance of Verticillium resistance in the diploid progenitor species. Due to the self-incompatibility system, self-fertilization is prevented and homozygous lines cannot be produced for inheritance studies.

With the help of embryo rescue techniques it is possible to generate novel, resynthesized (RS) oilseed rape lines comprising the intact genomes of the respective $B$. rapa and $B$. oleracea donor lines. Such RS B. napus represents an important source of novel genetic variation for specific traits in oilseed rape. In previous investigations this strategy has been adopted for introduction of resistance genes into B. napus against Turnip yellows virus (TuYV) (8), Turnip mosaic virus (TMV) (22), and also important fungal pathogens including Phoma lingam (3) and Plasmodiophora brassicae (5). A similar strategy has great promise for $V$. longisporum-resistance breeding, since numerous $B$. oleracea gene bank accessions are known with a high level of resistance to this pathogen, and their transfer to B. napus was found to improve the resistance of some of the resulting RS oilseed rape lines (11).

Widespread use of specific resistances from single donor sources induces a strong selection pressure on the pathogen that can result in the resistance being rapidly overcome. This has been shown previously for some of the above mentioned resistances 
derived only from B. rapa or B. oleracea sources $(10,20)$. It is therefore desirable to combine different resistance resources with potentially different mechanisms to generate long-term resistance, and to avoid the formation of new pathotypes with enhanced aggressiveness. The aim of the present study was to identify new resistance sources against $V$. longisporum among $B$. rapa gene bank material, and to combine these with known B. oleracea resistance sources in novel RS B. napus lines via sexual interspecific hybridization with the help of embryo rescue. The material that was developed is discussed regarding the potential for resistance breeding in oilseed rape and further investigations in Verticillium research.

\section{MATERIALS AND METHODS}

Plant materials. Twenty-nine $B$. oleracea and 12 B. rapa gene bank accessions (Table 1) obtained from eight different gene banks and a commercial seed supplier, were screened for their resistance response to $V$. longisporum in order to identify resistant genotypes for combination of potentially different resistances in RS B. napus. Parallel to the resistance screening of the diploid progenitors, a set of potentially resistant RS B. napus genotypes were generated by interspecific hybridizations. The parents of these crosses were different plants belonging to two $B$. rapa accessions that were chosen based on prior observations which indicated that these accessions could contain potential resistance to $V$. longisporum, and five $B$. oleracea gene bank accessions that were reported by Happstadius et al. (11) to have a high level of resistance to $V$. longisporum. The origins of the diploid accessions used for the interspecific crosses along with the pedigrees of the resulting RS lines are shown in Table 2.

The $B$. rapa genotypes were emasculated and hand-pollinated 2 days later with pollen from the respective $B$. oleracea parent, except in one case where the $B$. oleracea accession was used as the maternal parent and pollinated by B. rapa. To enhance the efficiency of the interspecific crossing, the embryo rescue technique was used to regenerate haploid plants in vitro. Immature pods were harvested 2 weeks after pollination and surface sterilized with $\mathrm{NaOCl}(3 \%)$ for $10 \mathrm{~min}$ and washed with sterile water. Ovules were dissected and cultivated on Murashige and Skoog (MS) media with sucrose (10 g/liter) (15) in a growth chamber at $20^{\circ} \mathrm{C}, 75 \%$ humidity and a day length of approximately $16 \mathrm{~h}$. Ovules that did not germinate after 6 weeks were transferred to new media, while germinated ovules that had already developed into a small plant were transferred to MS media containing saccharose (30 g/liter). Regenerated, vigorous plants were transferred to soil, and cuttings from the haploid hybrids were treated with colchicine $(0.05 \%$ colchicine, $0.15 \%$ dimethyl sulfoxide) for $12 \mathrm{~h}$ in the dark in order to obtain amphidiploid B. napus plants. All resulting RS plants were selfpollinated for seed multiplication by bagging with super-micro perforated Crispac bags (Baumann Saatzuchtbedarf, Waldenburg, Germany) before the onset of flowering. A total of 45 RS plants derived from 8 different $B$. rapa $\times$ B. oleracea cross combinations produced sufficient seeds $(>50)$ for the resistance screening.

Resistance screening. Resistance tests were performed using the V. longisporum isolates VL 43 and VL 40, which originate from B. napus grown in northern Germany (23). Long-term

TABLE 1. Accession numbers and sources of Brassica rapa and B. oleracea gene bank accessions that were phenotyped for identification of potential resistance to Verticillium longisporum

\begin{tabular}{lll}
\hline Species & Accession names & Source $^{\mathrm{a}}$ \\
\hline B. rapa & 13444, 56429, 56515 & BAZ \\
& G454 (Chinese cabbage 'Granat'), G684 ('Runde weiße rotköpfige Herbstrüben') & Cultivars \\
& YS Pb-24 (Yellow Sarson cultivar) & HAU \\
& Q3F, 'Reward', SWSP, 00 B. rapa & NPZ \\
& 03-510001 ('Salut'), 03-510002 ('Credit') & SW \\
B. leracea & 2398, 2808, 3775, 4250, 4622, 4707, 5085, 5394, 6206, 6704, 7518, 7799, 8207, 10590, 10618 & HRI \\
& BRA504, BRA544, BRA723, BRA809, BRA1008, BRA1355, BRA1398, BRA1427 & IPK \\
& CGN07069, CGN07089, CGN14044 & CGN \\
& 1227 & Li et al. 2001 (14) \\
& 1428,2070 & NIV \\
\hline
\end{tabular}

a BAZ: Gene bank of the Federal Centre for Breeding Research on Cultivated Plants, Braunschweig, Germany; CGN: Centre for Genetic Resources, Wageningen, Netherlands; HAU: Haryana Agricultural University, Hisar, India; HRI: Horticulture Research International Genetic Resources Unit, Warwick, UK; IPK: Institute of Plant Genetics and Crop Plant Research, Gatersleben, Germany; NIV: Gene bank of the NI Vavilov Institute of Plant Industry (VIR), St. Petersburg, Russia; NPZ: Norddeutsche Pflanzenzucht Hans-Georg Lembke KG, Hohenlieth, Germany; SW: Svalöf Weibull AB, Svalöf, Sweden.

TABLE 2. Origin of resynthesized oilseed rape lines and progenitor species with resistance to Verticillium longisporum

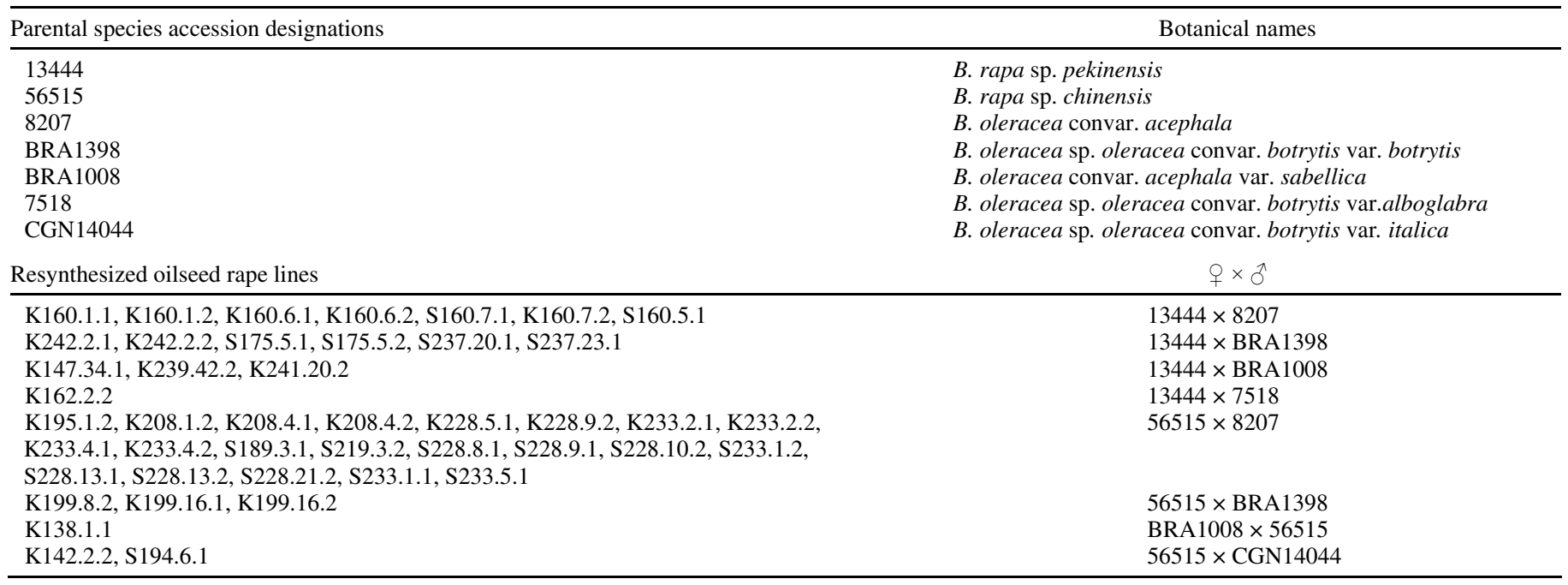


storage was performed as conidial suspensions in a concentration of 1 to $3 \times 10^{6}$ conidia/ml in Czapek-Dox medium $(4,7)$ supplemented with $25 \%$ glycerol. Inoculum was produced by adding $500 \mu \mathrm{l}$ of spore stock solutions to $250 \mathrm{ml}$ of potato dextrose broth. The cultures were subsequently incubated for 7 days at $23^{\circ} \mathrm{C}$ on a rotary shaker (100 RPM). The resulting suspension was filtered through sterile gauze. Spore concentration was determined with a hemacytometer and diluted to give $1 \times$ $10^{6}$ spores $\mathrm{ml}^{-1}$.

The winter oilseed rape cultivars, 'Express' (moderately tolerant) and 'Falcon' (highly susceptible), were used as controls in all experiments. Seeds of the control and test plants were surfacesterilized by immersion in $70 \%$ ethanol for $15 \mathrm{~min}$. Subsequently, the seeds were washed in sterilized tap water before being sown in double-autoclaved silica sand. Seedlings appeared after 3 to

TABLE 3. Assessment key for scoring disease severity of Verticillium longisporum in Brassica species using the root dip inoculation method

\begin{tabular}{ll}
\hline Score & \multicolumn{1}{c}{ Symptom development } \\
\hline 1 & No symptoms \\
2 & Symptoms (yellowing, black veins) on the youngest leaves \\
3 & Symptoms on the next older leaves \\
4 & $\leq 50 \%$ of leaves show symptoms \\
5 & $>50 \%$ of leaves show symptoms \\
6 & $\leq 50 \%$ of leaves are dead \\
7 & Only shoot meristem still alive \\
8 & Plant is dead \\
\hline
\end{tabular}

7 days, and 7 days later the roots were carefully washed out of the sand. Inoculations were performed by cutting $2 \mathrm{~cm}$ off the root apex and submerging the capped roots for $30 \mathrm{~min}$ in a mixed conidial suspension $\left(10^{6} \mathrm{ml}^{-1}\right)$ of both $V$. longisporum isolates VL 43 and VL 40. Roots of control plants were also cut and submerged in tap water for the same length of time. A total of 24 inoculated seedlings and 24 control plants of each accession were transferred into a mixture of sand, peat, and compost $(1: 1: 2)$ in pots containing two plants each. Plants were grown at $23^{\circ} \mathrm{C}$ in a greenhouse with a lighting regime of $14 / 10 \mathrm{~h}$ (light/dark). Plants were not fertilized during the investigations. Each plant was scored weekly for disease symptoms over a 4-week time period using an assessment key (Table 3) slightly modified from Zeise (24).

Statistical analysis of data. For each accession tested, the area under the disease progress curve (AUDPC) was calculated from the disease severity values according to the following formula from Campbell and Madden (1): AUDPC $=\Sigma\left(y_{i}+y_{i+1} / 2\right) \times\left(t_{i+1}-\right.$ $t_{i}$ ), where $y_{i}$ is the disease severity value for observation number $i$, $t_{i}$ is the number of days after inoculation at the time point of observation number $i$, and $n$ is the number of observations. To compensate for a fluctuating infection level between the trials a correction of the AUDPC value for each accession was made based on the reaction of the internal controls. The corrected value $\left(\mathrm{AUDPC}_{\mathrm{corr}}\right)$ was calculated as follows:

$$
A U D P C_{\text {corr }}=\frac{A U D P C}{\left(A U D P C_{\text {Express }}+A U D P C_{\text {Falcon }}\right) / 2}
$$
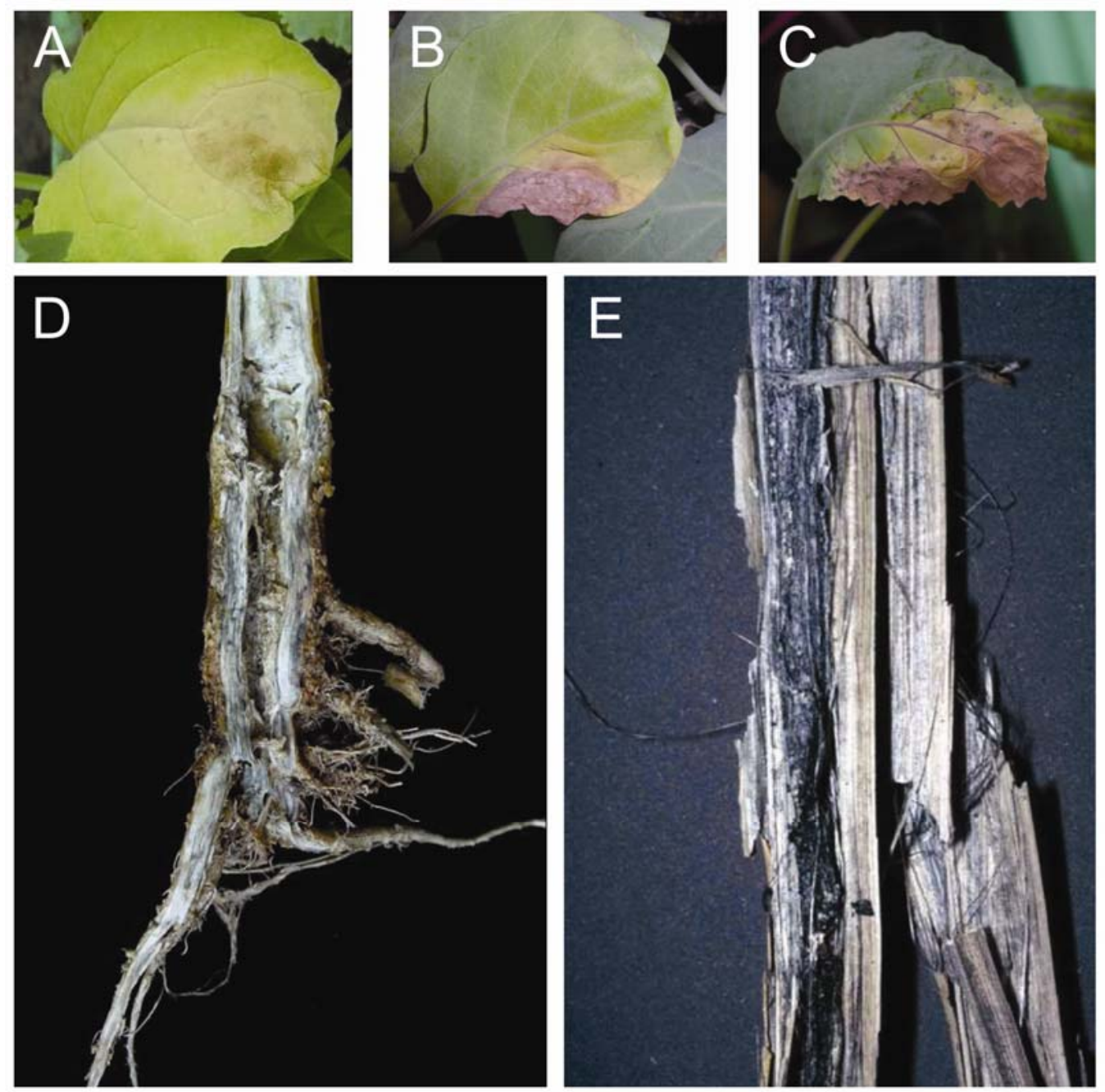

Fig. 1. Typical Verticillium longisporum disease symptoms on A, B, and C, young leaves, D, roots, and E, stem of Brassica napus plants. 
Phenotype data of RS lines was statistically analyzed with the software package SAS 9.1 (SAS Institute, Cary, NC). A general linear model procedure was used to identify RS lines with a significantly lower AUDPC $_{\text {corr }}$ value than cultivar Express, which in comparison to other currently available European winter oilseed rape cultivars shows a relatively high tolerance to V. longisporum (11).

\section{RESULTS}

Resistance screening. A broad range of resistance was observed among the tested materials. Examples of disease symptoms in susceptible oilseed rape plants are shown in Figure 1. Resistance responses of the tested $B$. rapa and $B$. oleracea genotypes, along with the oilseed rape controls, 'Express' and 'Falcon', measured by AUDPC corr $_{\text {value, are shown in Figure } 2 .}$ The tested plants of the B. oleracea accessions showed predominantly good resistance. With the exception of five accessions, the resistance phenotype was verified in all of the $B$. oleracea lines that were reported as $V$. longisporum-resistant by Happstadius et al. (11). In addition, two new resistant $B$. oleracea genotypes were identified, namely accession 1428 (white cabbage 'Kashirka 202') and accession 2070 (white cabbage 'Ladozhskaya'). The tested plants of both of these accessions showed consistently good resistance, with mean $\mathrm{AUDPC}_{\text {corr }}$ values comparable to the most resistant cabbage accessions identified by Happstadius et al. (11).

In comparison to the relatively high level of resistance among the $B$. olerace a accessions, the B. rapa accessions exhibited a predominantly susceptible or only moderately resistant phenotype. The highest level of susceptibility was observed in the Indian
Yellow Sarson cv. YS Pb-24. On the other hand, the accessions 13444 and G454 'Granat' showed moderate resistance phenotypes. However, of these two potentially promising $B$. rapa resistance donors, only the accession 13444 gave rise to RS plants that produced sufficient seed for resistance screening. A total of 18 RS lines with sufficient seed were produced from $B$. rapa accession 13444, crossed with various resistant $B$. oleracea accessions. The remaining $27 \mathrm{RS}$ lines that produced sufficient seed for pathogenicity testing all derived from the moderately susceptible $B$. rapa accession 56515, suggesting that the other $B$. rapa accessions that were used may have a negative effect on fertility or fecundity of the resulting RS genotypes.

The 45 RS lines that were tested in the pathogenicity screening showed a large variation in their response to $V$. longisporum infection (Fig. 3). This reflects the heterozygous nature of the $B$. rapa and $B$. oleracea gene bank accessions, which were in most cases self-incompatible. Statistical data analysis of $\mathrm{AUDPC}_{\text {corr }}$ values of all RS lines in relation to the control cultivar Express, confirmed that $37 \mathrm{RS}$ lines $(82 \%)$ showed significantly lower symptom scores $(P \leq 0.0194)$ than the moderately tolerant control. Unexpectedly, the RS lines derived from the moderately susceptible $B$. rapa accession 56515 showed significantly higher resistance $(P=0.001)$ than RS lines derived from crosses with the more resistant $B$. rapa accession 13444, irrespective of the $B$. oleracea resistance donor. This implies that the resistance factors from the respective $B$. oleracea donors are more effective in combination with resistance from the $B$. rapa accession 56515 . The seven most resistant RS lines were derived from crosses between plants of $B$. rapa accession 56515 and $B$. oleracea accession 8207. Interestingly, none of the RS lines derived from

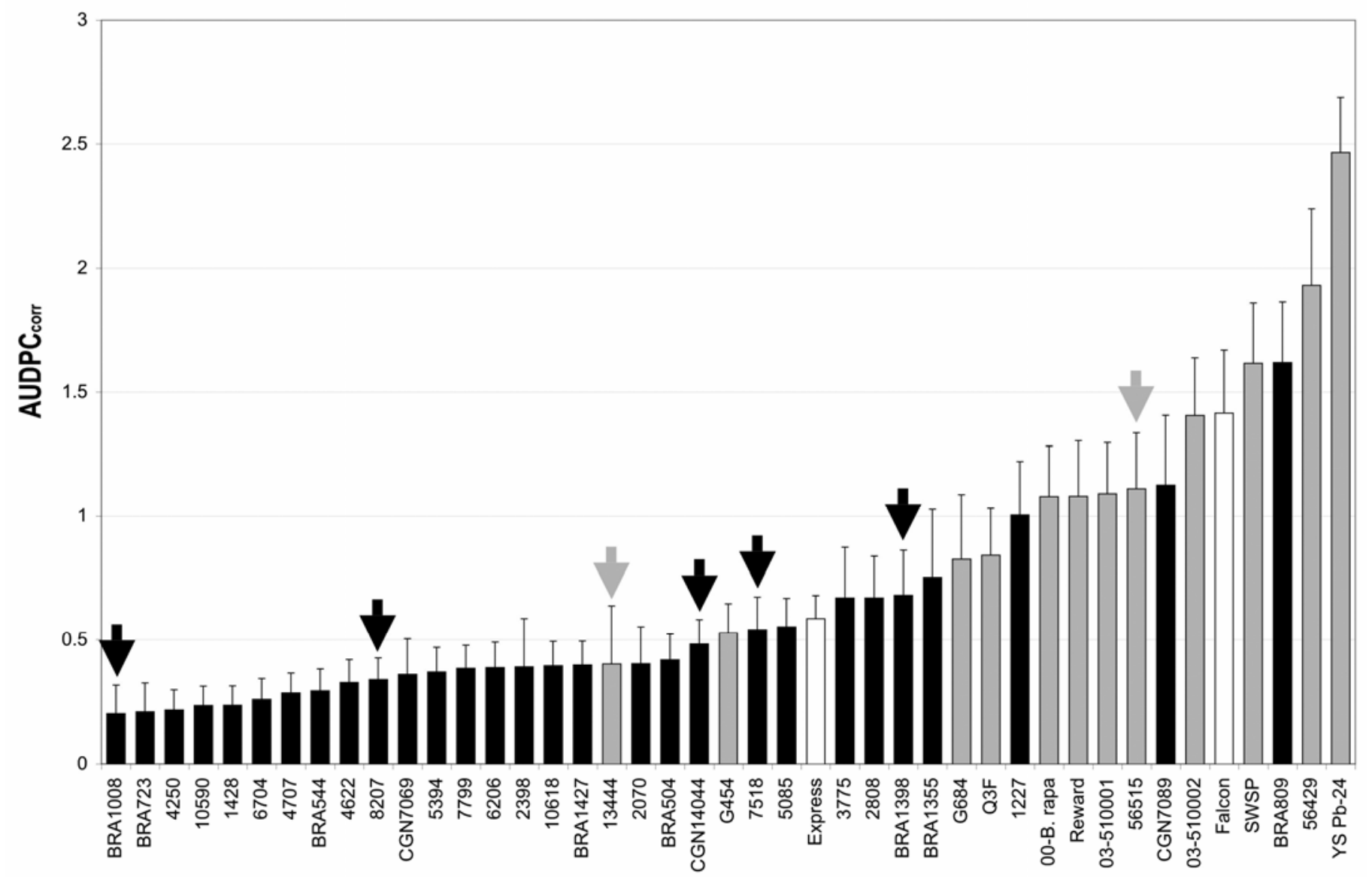

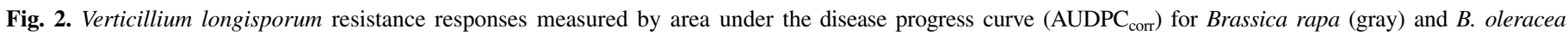

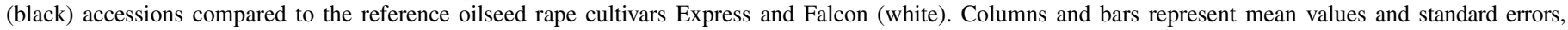

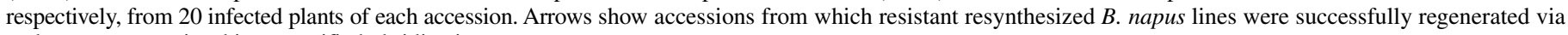
embryo rescue-assisted interspecific hybridization. 
the cross B. rapa $13444 \times$ B. oleracea 8207 showed a high level of resistance, suggesting a possible antagonism between the respective resistance mechanisms of these two donors. On the other hand, the high resistance of the RS lines from $B$. rapa $56515 \times$ B. oleracea 8207 in comparison to the lines from $B$. rapa $13444 \times$ B. oleracea 8207 appears to confirm that we have succeeded in effectively combining two different $B$. olerace $a$ and $B$. rapa resistance sources in $\mathrm{RS}$ oilseed rape genotypes with a high level of quantitative resistance.

\section{DISCUSSION}

Broadening the narrow genetic basis of B. napus through interspecific or intergeneric hybridization is an important strategy for resistance breeding. The Brassica B-genome species B. juncea, $B$. carinata, and $B$. nigra have been used in many studies to transfer resistance against Leptosphaeria maculans to oilseed rape $(2,6,17,18,21)$, however the development of new oilseed rape cultivars with B-genome resistance has proved difficult in many cases. On the other hand the use of B. rapa and B. oleracea genotypes as resistance donors can circumvent this problem because these are the ancestral parents of B. napus and their chromosomes have remained more or less intact in the amphidiploid genome (16). Crouch et al. (3) and Diederichsen and Sacristan (5) successfully transferred resistance against L. maculans and Plasmodiophora brassicae, respectively, from $B$. rapa to $B$. napus. These two studies led to the development of new winter oilseed rape cultivars carrying resistance to blackleg and clubroot disease, respectively. However, in both cases the resistance was overcome in a relatively short time by virulent pathogen races. On the other hand, the identification of genetically diverse resistance sources in different $B$. rapa and $B$. oleracea accessions opens the possibility for direct combination of different resistance genes. Combination or pyramiding of resistance sources can potentially provide a more durable and sustainable resistance.
In the present study two previously unknown $B$. oleracea sources of Verticillium resistance (accessions 1428 and 2070) were identified and the resistance phenotypes of other cabbage accessions were verified. Moreover, a resistance screening of B. rapa accessions led to the discovery of two lines (accessions 13444 and G545) with moderate resistance to $V$. longisporum. The combination of different $B$. oleracea and $B$. rapa resistance in RS B. napus resulted in a high level of resistance that in some cases surpassed the expectation based on the resistance levels observed in the respective parental lines. The best-performing interspecific hybrids showed considerably higher resistance than the variety Express, one of the most $V$. longisporum-tolerant cultivars available in Germany. Particularly high resistance was achieved in RS lines derived from combination of $B$. rapa accession 56515 and B. oleracea 8207, although other B. rapa parents showed higher levels of resistance

Standard errors of the means were clearly higher in the resistance experiment of the B. rapa and B. oleracea lines, which can be explained by the heterogeneous condition of the material. Diploid Brassica species possess a sporophytic homomorphic self-incompatibility system that prevents self-fertilization and promotes outbreeding. For this reason it can be assumed that many of the donor plants that were used for the interspecific hybridizations may have been heterozygous at the relevant resistance gene loci. This suggestion is supported by the large variation of resistance response among the RS lines derived from the same resistant accessions. By crossing these heterozygous plants, many different combinations of resistance sources are possible in the progenies. The most resistant RS phenotypes can be expected to represent an accumulation of the most effective genes in a single homozygous $B$. napus genotype. The sporophytic selfincompatibility common in the diploid Brassica species is generally suppressed in the amphidiploid B. napus. However, we observed a great variation among the RS plants in their selffertility and fecundity. The resistant lines described here, how-

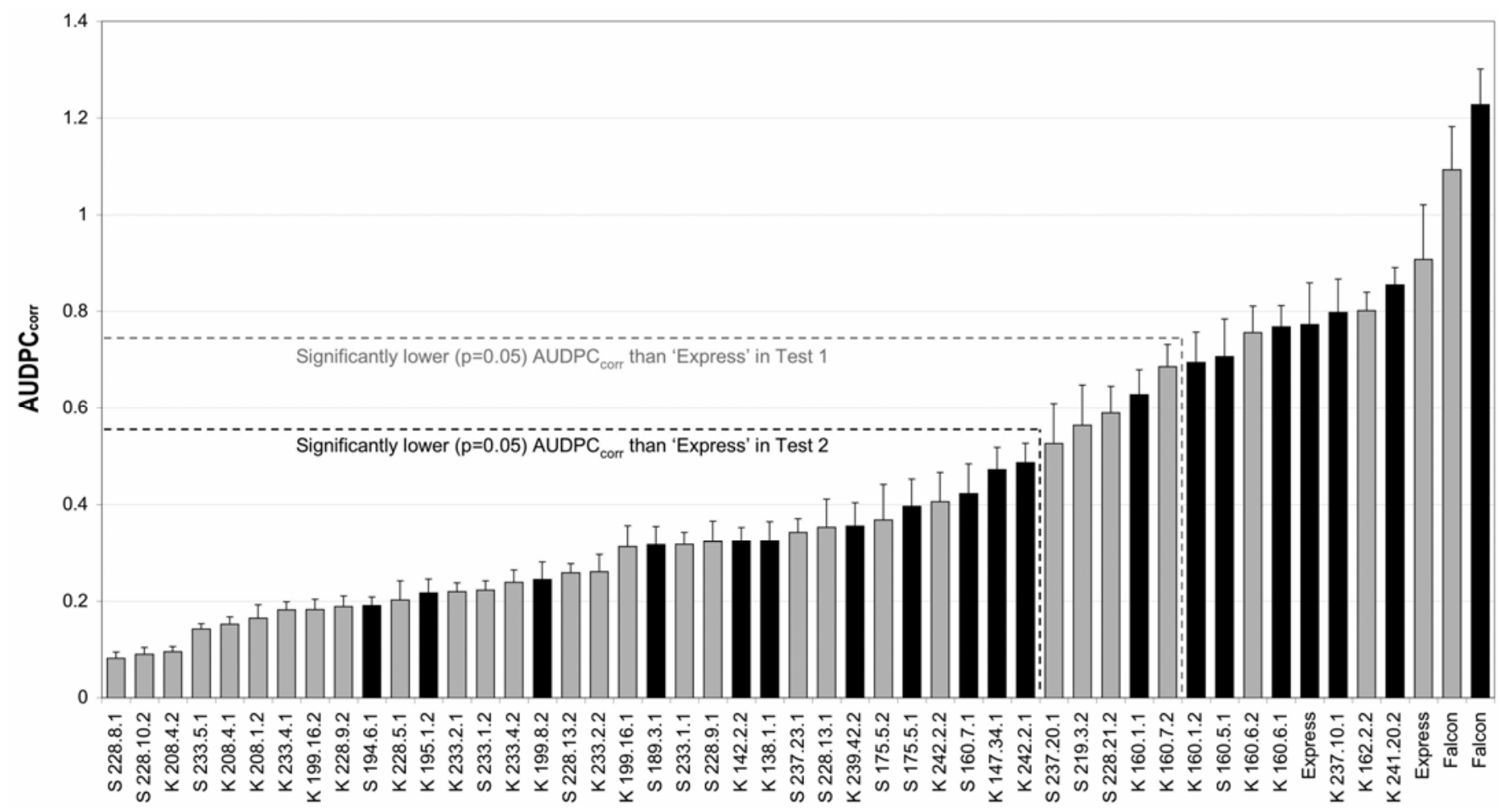

Fig. 3. Verticillium longisporum resistance responses of 45 resynthesized oilseed rape lines, along with the reference oilseed rape cultivars Express and Falcon, measured by normalized areas under the disease progress curve $\left(\mathrm{AUDPC}_{\mathrm{corr}}\right)$. The light and dark bars represent results from two independent resistance experiments (test 1 and 2) along with the respective controls from each of the two tests. Columns and bars represent mean values and standard errors, respectively, from 20 infected plants of each accession. The dashed horizontal lines show the significance levels $(P=0.05)$ in each of the two tests for significantly lower $\mathrm{AUDPC}_{\text {corr }}$ than Express in the respective resistance tests. 
ever, showed a good self-fertility and high seed-set, hence they are useful candidates for backcross breeding towards introgression of the resistances into elite oilseed rape lines.

Simultaneous introgression of numerous different resistance loci can be difficult, particularly in the case of quantitative resistance. To ensure that resistant genotypes have as many contributing resistance loci as possible, the development of molecular markers for pyramiding of different A- and C-genome resistances (with potentially complementary resistance mechanisms) is desirable. For this purpose the different RS B. napus lines identified in the current study are presently being crossed to susceptible lines for the generation of segregating mapping populations. By testing such material both in greenhouse tests and under field conditions this should allow us to (i) study and compare the genetic basis of the different resistances, (ii) map quantitative trait loci for identification of selection markers closely linked to major resistance loci, and (iii) to select promising resistant oilseed rape lines for the development of new cultivars with resistance to $V$. longisporum.

\section{ACKNOWLEDGMENTS}

This work was funded by the Association for Promotion of Private German Plant Breeding (GFP) and the Agency for Renewable Resources (FNR) of the Federal Ministry for Nutrition, Agriculture, and Consumer Protection (BMELV). We thank R. Kürschner, S. Sahner, and J. Schaper for excellent technical assistance.

\section{LITERATURE CITED}

1. Campbell, C. L., and Madden, L. V. 1990. Introduction to Plant Disease Epidemiology. John Wiley, New York.

2. Chèvre, A. M., Eber, F., This, P., Barret, P., Tanguy, X., Brun, H., Delseny, M., and Renard, M. 1996. Characterization of Brassica nigra chromosomes and of blackleg resistance in B. napus-B. nigra addition lines. Plant Breed. 115:113-118.

3. Crouch, J. H., Lewis, B. G., and Mithen, R. F. 1994. The effect of A genome substitution on the resistance of Brassica napus to infection by Leptosphaeria maculans. Plant Breed. 112:265-278.

4. Czapek, F. 1902. Untersuchungen über die Stickstoffgwinnung und Eiweißbildung der Pflanzen. Breitr. Chem. Physiol. Pathol. 2:540-560.

5. Diederichsen, E., and Sacristan, M. D. 1996. Disease response of resynthesized Brassica napus L. lines carrying different combinations of resistance to Plasmodiophora brassicae. Wor. Plant Breed. 115:5-10.

6. Dixelius, C. 1999. Inheritance of the resistance to Leptosphaeria maculans of Brassica nigra and B. juncea in near-isogenic lines of $B$. napus. Plant Breed. 118:151-156.

7. Dox, A. W. 1910. The intracellular enzymes of Penicillium and Aspergillus with special references to those of $P$. camenberti. U.S. Dep. Agric. Bur. Anim. Ind. Bull. 120:1-170
8. Dreyer, F., Graichen, K., and Jung, C. 2001. A major quantitative trait locus for resistance to Turnip yellows virus (TuYV, syn. beet western yellows virus, BWYV) in rapeseed. Plant Breed. 120:457-462.

9. Dunker, S., Keunecke, H., and von Tiedemann, A. 2006. Verticillium longisporum in winter oilseed rape-Impact on plant development and yield. Integrated Control Oilseed Crops 29:365-374.

10. Fähling, M., Graf, H., and Siemens, J. 2003. Pathotype separation of Plasmodiophora brassicae by the host plant. J. Phytopathol. 151:425-430.

11. Happstadius, I., Ljungberg, A., Kristiansson, B., and Dixelius, C. 2003. Identification of Brassica oleracea germplasm with improved resistance to Verticillium wilt. Plant Breed. 122:30-34.

12. Heale, J. B., and Karapapa, V. K. 1999. The Verticillium threat to Canada's major oilseed crop: Canola. Can. J. Plant Pathol. 21:1-7.

13. Karapapa, V. K., Bainbridge, B. W., and Heale, J. B. 1997. Morphological and molecular characterization of Verticillium longisporum comb. Nov, pathogenic to oilseed rape. Mycol. Res. 101:1281-1294.

14. Li, L., Paolillo, D. J., Parthasarathy, M. V., DiMuzio, E. M., and Garvin, D. F. 2001. A novel gene mutation that confers abnormal patterns of $\beta$ carotene accumulation in cauliflower (Brassica oleracea var. botrytis). Plant J. 26:59-67.

15. Murashige, T., and Skoog, F. 1962. A revised medium for rapid growth and bioassays with tobacco tissue cultures. Physiol. Plant 15:473-497.

16. Parkin, I. A. P., Sharpe, A. G., Keith, D. J., and Lydiate, D. J. 1995. Identification of the A and $\mathrm{C}$ genomes of amphidiploid Brassica napus (oilseed rape). Genome 38:1122-1131.

17. Roy, N. N. 1978. A study on disease variation in the populations of an interspecific cross of Brassica juncea L. $\times$ B. napus L. Euphytica 27:145149 .

18. Sacristán, M. D., and Gerdemann, M. 1986. Different behavior of Brassica juncea and B. carinata as sources of Phoma lingam resistance in experiments of interspecific transfer to B. napus. Z. Pflanzenzuecht. 97:304-314.

19. Schnathorst, W. 1981. Life cycle and epidemiology of Verticillium. Pages 81-111 in: Fungal Wilt Diseases of Plants. M. E. Mace, A. A. Bell, and C. H. Beckmann, eds. Academic Press, London, UK.

20. Sprague, S. J., Balesdent, M. H., Brun, H., Hayden, H. L., Marcroft, S. J., Pinochet, X., Rouxel, T., and Howlett, B. J. 2006. Major gene resistance in Brassica napus (oilseed rape) is overcome by changes in virulence of populations of Leptosphaeria maculans in France and Australia. Eur. J. Plant Pathol. 114:33-40.

21. Struss, D., Quiros, C. F., Plieske, J., and Röbbelen, G. 1996. Construction of Brassica B genome synteny groups based on chromosomes extracted from three different sources by phenotypic, isozyme and molecular markers. Theor. Appl. Genet. 93:1026-1032.

22. Walsh, J. A., Sharpe, A. G., Jenner, C. E., and Lydiate, D. J. 1999. Characterization of resistance to turnip mosaic virus in oilseed rape (Brassica napus) and genetic mapping of TuRB01. Theor. Appl. Genet. 99:1149-1154.

23. Zeise, K., and von Tiedemann, A. 2001. Morphological and Physiological Differentiation among vegetative compatibility groups of Verticillium dahliae in relation to V. longisporum. J. Phytopathol. 149:469-475.

24. Zeise, K. 1992. Gewächshaustest zur Resistenzprüfung von Winterraps (Brassica napus L. var. oleifera Metzger) gegen den Erreger der Rapswelke Verticillium dahliae Kleb. Nachrichtenbl Deutscher Pflanzenschutzd 44:125-128. 